\title{
Economic and environmental benefits of a novel multi-functional heat pump system for dishwasher
}

\author{
Wei Dong ${ }^{1,2, *}$, Yongcun $\mathrm{Li}^{1}$ \\ ${ }^{1}$ School of Civil Engineering, Hunan University of Science and Technology, Xiangtan 411201, China \\ ${ }^{2}$ School of Construction Engineering, Xinyu University, Xinyu 338000, China
}

\begin{abstract}
In present study, a novel heat pump named multi-functional heat pump systems for dishwashers is introduced. $45^{\circ} \mathrm{C}$ hot water cycle and hot air cycle are provided by the single-stage heat pump cycle to complete the cleaning and drying process. Moreover, the high temperature water at $85{ }^{\circ} \mathrm{C}$ is provided by the two-stage heat pump cycle system to achieve the disinfection function, and the $26^{\circ} \mathrm{C}$ cold air is realized by the single-stage refrigeration cycle for rapid cooling. Thermodynamic analysis of multi-functional heat pump systems for dishwashers under four different operating conditions with R22 / R134a as working fluid was carried out. The results show that COP (coefficient of performance) of the system is above 3.2 under all four conditions, which meets the energy efficiency rating index. Comparing energy efficiency and environmental benefits and operating costs of multi-functional heat pump systems for dishwashers with the traditional electric heating dishwashers, these can be known that primary energy consumption, carbon dioxide emissions and operating cost of multifunctional heat pump dishwasher are $1.24 * 10^{5} \mathrm{~kJ}, 10.55 \mathrm{~kg}$ and 21.70 Yuan respectively under the condition of per running energy consumption for $40 \mathrm{~kW} \cdot \mathrm{h}$, above three all lower than the traditional electric heating dishwasher.
\end{abstract}

\section{Introduction}

Environmental protection and the sustainable use of energy have drawn great attention from all countries in recent years. Highlighting PM2.5, the greenhouse effect and other issues, also the efficient use of energy have become urgent problems to be solved. Air-source heat pump has been widely used in many fields, as device which can improve the low-grade energy to high-grade energy and consume the less heating energy. With the national policy of coal to electricity put forward in China, heat pump has been more widely concerned for its effective energy conservation and reducing $\mathrm{CO}^{2}$ emissions.

In recent years, many experimental, theoretical and economic studies have been reported on heat pump technology. Rui et al. proposed single-stage compression heat regenerative cycle of zeotropic refrigerant mixtures concept, they get the result that the reasonable component ratio of R23 / R600a is 3: 7 [1]. Chen et al. studied on the control about stability of the cascade air-source heat pump system [2]. It is concluded that the cascade heat pump system is stable and reliable by adopting the principle of the second stage compression ratio is approximately equal to the optimal middle pressure which determined corresponding to the optimal middle temperature. Yu et al. proposed single-two stage hybrid cascade airsource heat pump unit, acted the coefficient of heating performance as the optimization objective, and determined the ambient temperature $0{ }^{\circ} \mathrm{C}$ for the system is the single-two stage switching conditions [3]. Zhang et al. proposed air source heat pump can be composed to various systems as different equipment to meet various functional [4]. Bo et al. studied the air source integrated heat pump [5]. They obtained that by recovering condensing waste heat in the cooling season can lead to significant energy savings. Meanwhile, advantages of the cascaded system are small value of compression ratio, higher pressure and exit temperature of the compressor. Almahdi et al. studied a potential cascaded vapor compression heat pump that is proposed to address the high temperature heat demand in the copper chlorine $(\mathrm{Cu}-\mathrm{Cl})$ thermochemical cycle for hydrogen production [6]. It concluded that such cascaded heat pumps utilize industrial waste heat as the heat source can meet $\mathrm{Cu}_{2} \mathrm{OC}_{12}$ decomposition reactor heat demand. Wang et al. studied an air-source heat pump system [7]. They concluded that system COP can reach 3.4 when inlet air temperature of evaporator and condenser inlet water temperature reached the set temperature. At present, the research of air-source heat pump system mainly focuses on the optimization of

\footnotetext{
* Corresponding author: $17053359 @$ aq.. com
} 


\begin{tabular}{|ccc}
\hline $\begin{array}{c}\text { Nomenclature } \\
\text { COP }\end{array}$ & $\begin{array}{c}\text { Subscripts } \\
\text { coefficient of performance } \\
\text { heat transfer per mass }[\mathrm{kW} / \mathrm{kg}] \\
\text { specific enthalpy }[\mathrm{kJ} / \mathrm{kg}]\end{array}$ & $\mathrm{h}$ \\
$m$ & mass flow rate $[\mathrm{kg} / \mathrm{s}]$ & $1,2 \ldots$ \\
$w$ & Power consumption per mass $[\mathrm{kW} / \mathrm{kg}]$ & $\mathrm{M}$ \\
$Q$ & heat exchange $[\mathrm{kW}]$ & $\mathrm{T}$ \\
$W$ & power consumption $[\mathrm{kW}]$ & $\mathrm{hc}$ \\
$T$ & Celsius temperature,$\left[{ }^{\circ} \mathrm{C}\right]$ & $\mathrm{ge}$ \\
& & ee \\
& & ap
\end{tabular}

Greek letters

ae efficiency

system working fluid, the control stability of the system, the improvement of system performance and so on, mainly for only heating or cooling mode. With the development of people's living standards, the mere heating or cooling mode of operation cannot meet the diverse needs [8].

The literature survey indicates that studies on multifunctional heat pump system are still lacking. Heat pump as an effective energy-saving measures, can achieve a variety of heating or cooling functions. This study aims to develop a multifunctional heat pump system for dishwashers, which present four different operation modes including hot water, hot air, cold air and high temperature water. Single stage cycle can be used to provide hot water for cleaning and hot air for drying, and cold air is used to rapidly cool the cleaned dishes, and the high temperature water provided by the two-stage cycle is used to disinfect the dishes. Performance analysis of the operating modes under different operating conditions is carried out in order to provide reference for design of the multifunctional heat pump system.

\section{Principle of multifunctional heat pump system for dishwasher}

The schematic of multi-functional heat pump system for dishwashers are shown in Fig.1. The working fluid of the system is R22 and R134a, in which R22 is the refrigerant of single-stage heat pump cycle and R134a for two-stage heat pump cycle. This system consists of ten major components include compressor 1, 4-way valve, air evaporator, throttle valve 1, air heat exchanger 1, water heat exchanger 2 , evaporative condenser, compressor 2, water heat exchange 3 and throttle valve 2 . The proposed multi-functional heat pump system has four operating modes: hot water, hot air, cold air and high temperature water. heating cycle
refrigeration cycle
state numbers

multifunctional heat pump dishwasher

traditional electric heating dishwasher

heat consumption grid transmission efficiency electric water heater heating efficiency air heat pump national average power generation efficiency

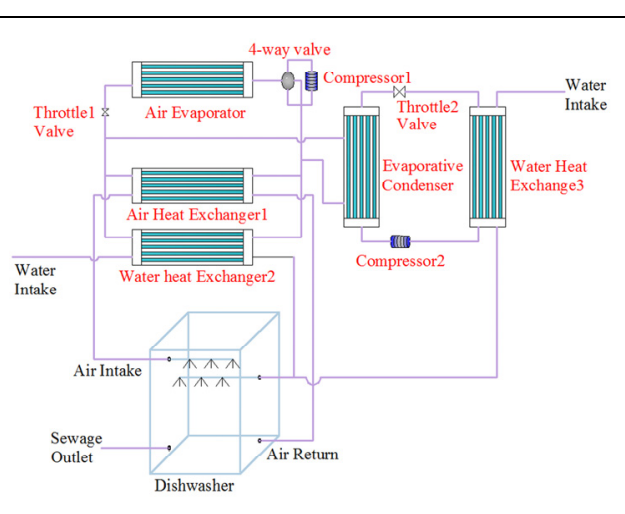

Fig. 1 Schematic of multifunctional heat pump system for dishwasher

\subsection{Hot water cycle mode}

Fig.2 shows the hot water cycle mode that consists of compressor 1, 4-way valve, air evaporator, throttle valve 1 and water heat exchanger 2 . It is observed that the hot water cycle works between two main pressure levels: low pressure in the air evaporator and high pressure in the water heat exchanger 2 . In water heat exchanger 2 , heat is released from high-temperature and high-pressure superheat refrigerant vapor to the water and provide hot water as $45{ }^{\circ} \mathrm{C}$ to complete the cleaning process. High temperature and high pressure refrigerant with subcool degree $5{ }^{\circ} \mathrm{C}$ flow into the throttle valve 1. After approximately isentropic throttling process, refrigerant turn into low temperature and low pressure vapor-liquid mixture, then flow into the air evaporator. In air evaporator, heat is absorbed from environment by refrigerant. Refrigerant go through isothermal heat process and turn to refrigerant vapor with superheat degree $5{ }^{\circ} \mathrm{C}$, finally flowing to compressor 1. After isentropically compressed, refrigerant vapor flow to the water heat exchanger 2 and complete hot water cycle mode. 

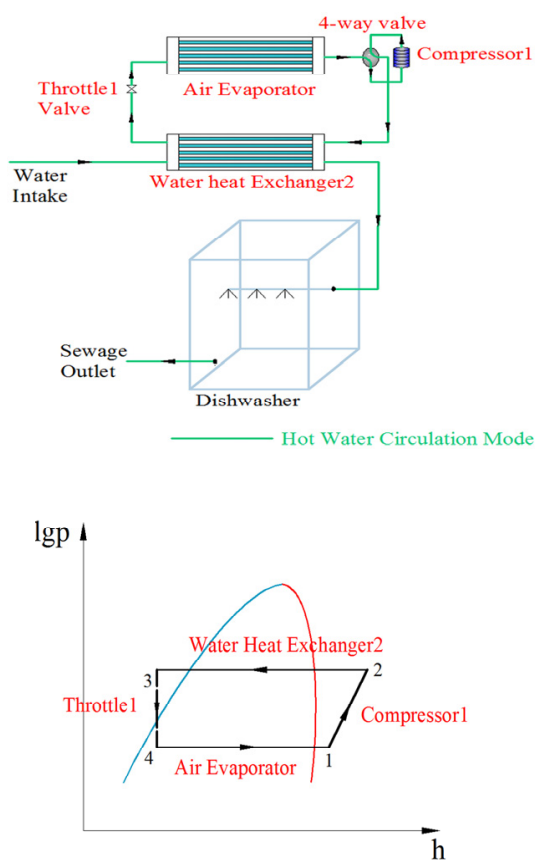

a) Flow diagram

b) Pressure enthalpy chart

Fig. 2. Hot water cycle mode flow chart of multifunctional heat pump system

\subsection{Hot air cycle mode}

The hot air cycle mode is shown in Fig.3. Hot air cycle mode consists of five major components include compressor 1, 4-way valve, air evaporator, throttle valve 1 and air heat exchanger 1. Compared the hot air cycle mode to the hot water cycle mode, the difference is that high-temperature and high-pressure superheated refrigerant vapor compressed by compressor 1 directly flow into air heat exchanger 1 . In air heat exchanger 1 , heat is released from the refrigerant vapor to the air which can provide hot air as $45^{\circ} \mathrm{C}$ and complete the drying process.

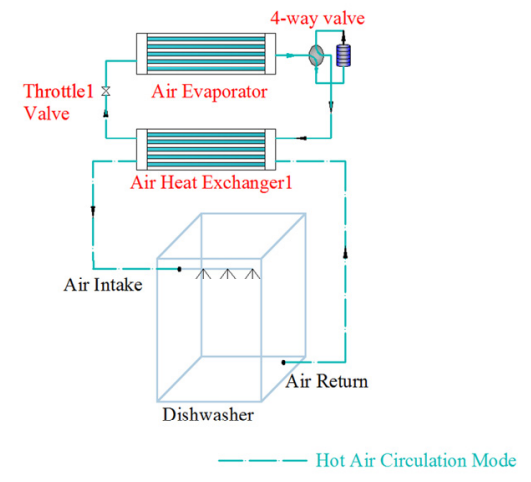

a) Flow diagram

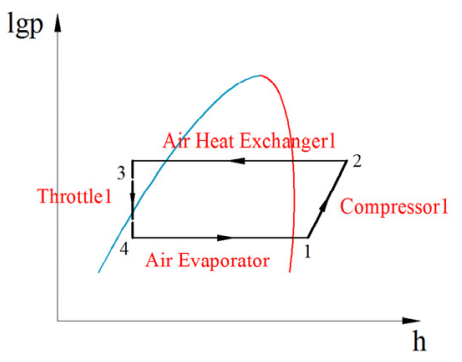

b) Pressure enthalpy chart

Fig. 3. Hot air cycle mode flow chart of multifunctional heat pump system

\subsection{Cool air cycle mode}

Cool air cycle mode is shown in Fig.4. The cold air cycle has the same components as the hot air cycle. It can be observed that the heat is released from the hightemperature and high-pressure superheat refrigerant vapor to the environment in air evaporator. Then, high temperature and high pressure refrigerant with subcool degree $5{ }^{\circ} \mathrm{C}$ flow into throttle valve 1 . Experiencing isentropic throttling process, refrigerant liquid turn into low temperature and low pressure vapor-liquid mixture and flow to the air heat exchanger. In air heat exchanger, heat is absorbed from the air by the refrigerant and provides cold wind as $26{ }^{\circ} \mathrm{C}$ for rapid cooling purpose. Refrigerant is compressed in compressor 1 and turn to superheated refrigerant vapor with superheat degree $5{ }^{\circ} \mathrm{C}$. Finally, refrigerant vapor flow back to air evaporator and complete cool air cycle mode. Compared the hot air cycle mode to the cool air cycle mode, the mainly difference is that the 4-way valves is used for reversing, refrigerant isothermally release heat in air evaporator and isothermally absorb heat in air heat exchanger 1 .

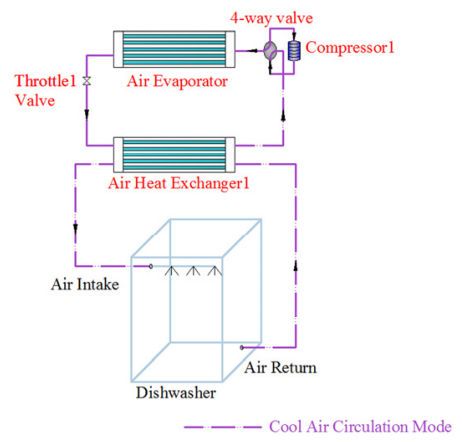

a) Flow diagram

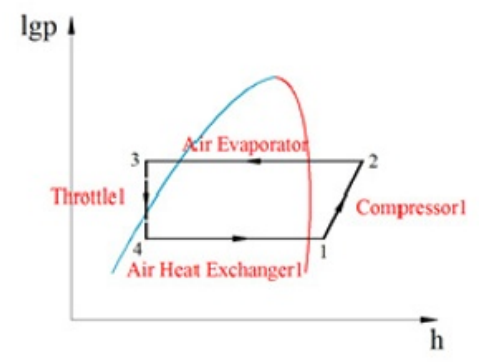

b) Pressure enthalpy chart 
Fig. 4 Cool air cycle mode flow chart of multifunctional heat pump system

\subsection{High temperature water cycle mode}

As shown in Fig.5, the high temperature water cycle system consists of compressor 1, 4-way valve, air evaporator, throttle valve 1 , evaporator condenser, compressor 2, water heat exchange 3 and throttle valve 2. According to Fig. 5, it is seen that the difference of high temperature water cycle system with the hot water cycle system is that the low temperature and low pressure vapor-liquid refrigerant absorb heat from air evaporator and enter the evaporation condenser. Then, isothermal heat exchange is performed in the evaporation condenser to complete the single-stage refrigeration cycle. After absorb heat in the evaporation condenser which generated by the single stage heating cycle, the high temperature grade refrigerant sequentially passes through the compressor 2 , the water heat exchange 3 , and the throttle valve 2 . Finally, refrigerant return to the evaporation condenser again and complete the two-stage high temperature water cycle.

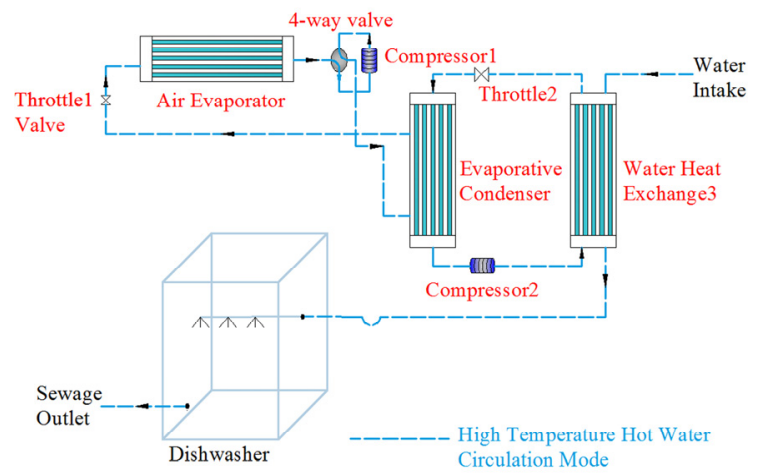

a) Flow diagram

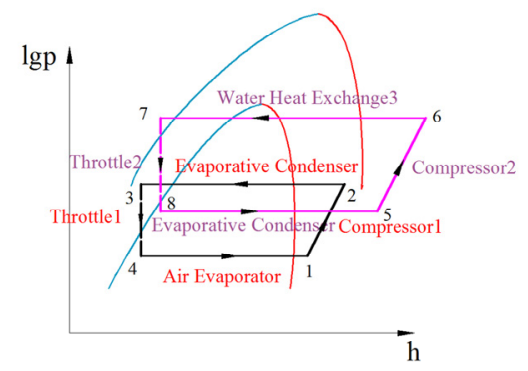

b) Pressure enthalpy chart

Fig. 5. High temperature water cycle mode flow chart of multifunctional heat pump system

\section{Analysis on performance of multifunctional heat pump system for dishwasher}

\subsection{The mathematical model of multifunctional heat pump system for dishwasher}

1) Single-stage heat pump and refrigeration cycle
The rate of heat transfer in evaporator of single-stage heat pump cycle:

$$
q_{1}=h_{1}-h_{4}
$$

The rate of heat transfer in condenser of single-stage heat pump cycle:

$$
q_{2}=h_{2}-h_{3}
$$

Specific enthalpy in throttle valve of single-stage heat pump cycle can be obtained:

$$
h_{3}=h_{4}
$$

Specific power consumption of compressor of singlestage heat pump cycle is defined by:

$$
w_{1}=h_{2}-h_{1}
$$

Heat transfer in evaporator of single-stage heat pump cycle:

$$
Q_{1}=M_{R}\left(h_{1}-h_{4}\right)
$$

Heat transfer in condenser of single-stage heat pump cycle:

$$
Q_{2}=M_{R}\left(h_{2}-h_{3}\right)
$$

Power consumption of compressor of single-stage heat pump cycle:

$$
W_{1}=M_{R}\left(h_{2}-h_{1}\right)
$$

The coefficient of performance for heating of singlestage heat pump cycle is determined from:

$$
C O P_{h}=\frac{Q_{2}}{W_{1}}=\frac{h_{2}-h_{3}}{h_{2}-h_{1}}
$$

The coefficient of performance for refrigerating of single-stage heat pump cycle is given by:

$$
\operatorname{COP}_{\mathrm{C}}=\frac{Q_{1}}{W_{1}}=\frac{h_{1}-h_{4}}{h_{2}-h_{1}}
$$

2) Two-stage heat pump cycle

Heat exchange in condenser of two-stage heat pump cycle:

$$
Q_{3}=M_{R}\left(h_{6}-h_{7}\right)
$$

Power consumption of compressor of two-stage heat pump cycle:

$$
W_{2}=M_{R}\left(h_{6}-h_{5}\right)
$$

The coefficient of performance for heating of twostage heat pump cycle is defined by:

$C O \mathrm{P}_{\mathrm{h} 2}=\frac{Q_{3}}{W_{1}+W_{2}}=\frac{h_{6}-h_{7}}{\left(h_{2}-h_{1}\right)+\left(h_{6}-h_{5}\right)}$

\subsection{Calculation results and analysis}

The ambient temperature is the dominating parameter that affects the performance of the heat pump. It not only affects heating capacity, power consumption, COP, but also affects the safety and reliability of the system operation. Therefore, the influence of ambient temperature on the performance of heat pump operating under different modes is focused in this paper. 


\subsubsection{The effect of ambient temperature on the performance under hot water cycle mode}

Fig.6 shows the influence of the ambient temperature on the performance of the heat pump when heat pump operate under hot water cycle mode as condensation temperature $50{ }^{\circ} \mathrm{C}$ and subcooling degree $5^{\circ} \mathrm{C}$.

It can be seen from Fig.6, the power consumption of compressor will decrease linearly with the increasing of ambient temperature. When the condensing temperature is $50{ }^{\circ} \mathrm{C}$, the ambient temperature increase from $10{ }^{\circ} \mathrm{C}$ to $15{ }^{\circ} \mathrm{C}$ and the power consumption of compressor reduce from 1.88 $\mathrm{kW}$ to $1.67 \mathrm{~kW}$, about $11.11 \%$. It mainly due to the ambient temperature increases, the compressor pressure ratio will decrease, and then the mass flow of refrigerant increases and the power consumption of compressor will reduce. Under the same operating conditions, $\mathrm{COP}$ of the system increases with the rise of ambient temperature, from 4.16 to 5.26, nearly $26.6 \%$. It mainly due to the increase of heating capacity is greater than the reduction of power consumption, the coefficient of performance increases. It can be seen from the above mentioned that when the ambient temperature increases, the power consumption of the hot water cycle mode also decreases, and the COP will increase.

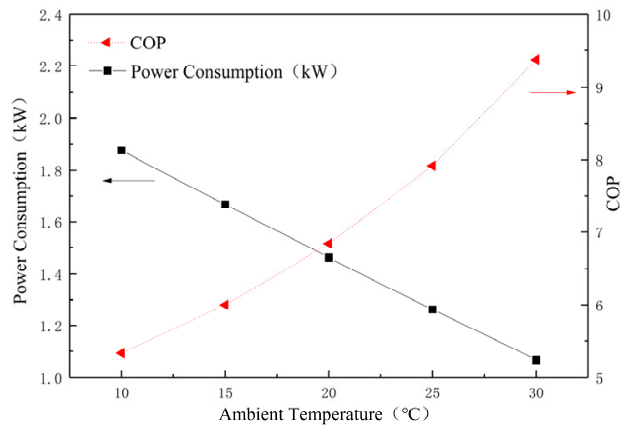

Fig. 6 Performance of hot water cycle mode

\subsubsection{The effect of ambient temperature on the performance of hot air cycle mode}

The variation of the power consumption of compressor and $\mathrm{COP}$ with ambient temperature is shown as Fig.7. It is also obviously indicates that power consumption of compressor and COP occur the same trend as under the hot air cycle mode and the hot water cycle mode. When the condensing temperature is $55{ }^{\circ} \mathrm{C}$, the ambient temperature increased from $10{ }^{\circ} \mathrm{C}$ to $15{ }^{\circ} \mathrm{C}$, the compressor power consumption decreased from $2.08 \mathrm{~kW}$ to $1.87 \mathrm{~kW}$, almost $11.3 \%$, meanwhile COP increase from 4.80 to 5.32 , about $11.3 \%$.

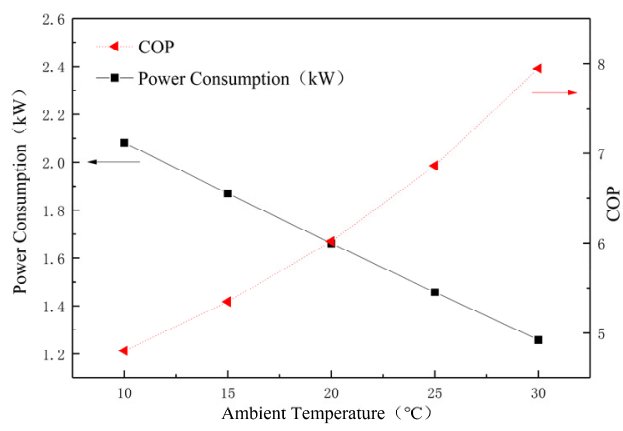

Fig.7 Performance of hot air cycle mode

\subsubsection{The effect of ambient temperature on the performance of cold air cycle mode}

The variation of the power consumption of compressor and COP with the ambient temperature is presented in Fig.8. The power consumption of compressor will rise approximately linearly with the increasing of ambient temperature. When the evaporation temperature is 16 ${ }^{\circ} \mathrm{C}$, the ambient temperature increased from $30{ }^{\circ} \mathrm{C}$ to $31{ }^{\circ} \mathrm{C}$ and the power consumption of compressor will increase from $1.09 \mathrm{~kW}$ to $1.18 \mathrm{~kW}$, about $8.3 \%$. It mainly due to the condensing temperature increase can lead to the condensing pressure of the system increase. As a result, the power consumption of the compressor also increases, the system COP decreased from 9.30 to 8.57 , nearly $7.8 \%$, the cooling capacity of the system will decrease and the power consumption will enhance, which lead to the system COP decrease. From the above, it can be seen that the system COP will reduce and power consumption of compressor will increase with the increase of the ambient temperature in the cool air cycle mode. It can be seen that there is an opposite trend between the hot water cycle mode and cool air cycle mode.

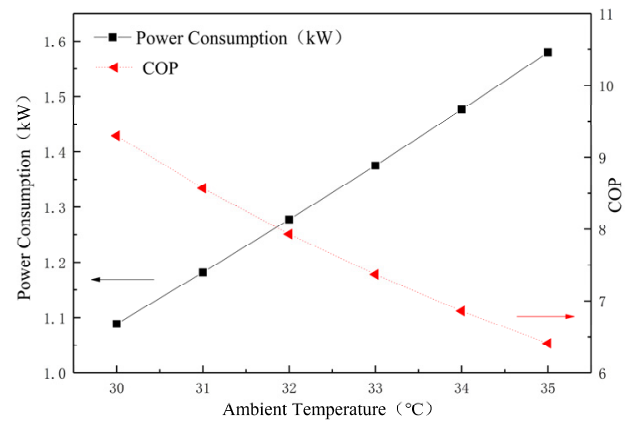

Fig. 8 Performance of cool air cycle mode

\subsubsection{The effect of ambient temperature on the performance of high temperature water cycle mode}

Fig.9 shows the variation of the power consumption of compressor and COP with ambient temperature. It is also illustrate that the power consumption of compressor will decrease approximately linearly with the increasing of ambient temperature. When the 
condensing temperature is $90{ }^{\circ} \mathrm{C}$, the ambient temperature increase from $10{ }^{\circ} \mathrm{C}$ to $15{ }^{\circ} \mathrm{C}$, and the power consumption of compressor reduce from $1.44 \mathrm{~kW}$ to $1.32 \mathrm{~kW}$, about $8.3 \%$. At the same time, as the ambient temperature increases, the system COP also increase from 3.22 to 3.73 , which is $15.8 \%$ increasing. The trend is similar to single stage hot cycle.

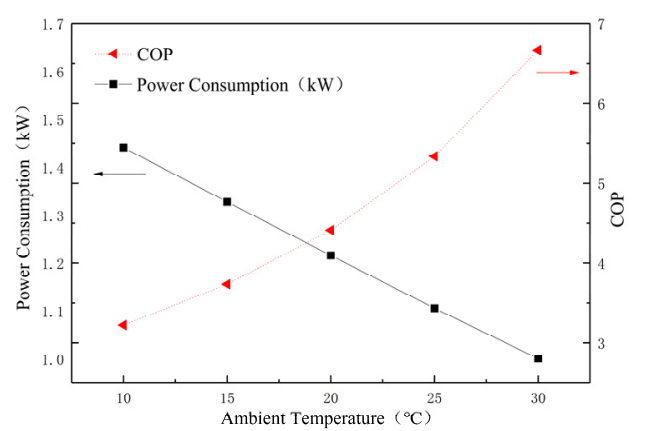

Fig. 9. Performance of high temperature water cycle mode

\section{Analysis on energy efficiency and environmental benefit of multifunctional heat pump for dishwasher}

At present, the energy source of the dishwasher is mainly electric energy. The energy sources of the multifunctional heat pump dishwasher described in this article is electric energy and air energy [9].The standard of coal heating value is $29.306 \mathrm{~kJ} / \mathrm{m}^{3}$ in China. According to China Energy Statistical Yearbook 2010, the standard of coal consumption of thermal power generation per kilowatt in China is $345 \mathrm{~kg}$. According to statistics, the carbon dioxide emissions is $2.493 \mathrm{~kg}$, sulfur dioxide emissions is $0.075 \mathrm{~kg}$, nitrogen oxides emissions is $0.0375 \mathrm{~kg}$ for the standard coal emissions of per kilogram. Regarding energy consumption of $40 \mathrm{KW}$ for dishwasher as benchmark, the energy efficiency, environmental benefits and the operating costs are compared between the traditional electric heating dishwashers and multifunctional heat pump dishwasher.
Heat consumption for $40 \mathrm{KWh}$ should be equal to:

$$
Q_{h_{c}}=40 * 3600=1.44 * 10^{5} \mathrm{~kJ}
$$

Primary energy consumption of traditional electric heating can be obtained as:

$$
Q_{T}=\frac{Q_{\mathrm{h}_{c}}}{\eta_{e e} \eta_{a e} \eta_{g e}}=4.71 * 10^{5} \mathrm{~kJ}
$$

Primary energy consumption of multifunctional heat pump dishwasher is determined from:

$$
Q_{M}=\frac{Q_{\mathrm{hc}}}{C O P_{a p} \eta_{a e} \eta_{g e}}=1.24 * 10^{5} \mathrm{~kJ}
$$

Where $Q_{h_{c}}$ denote the heat consumption; $\eta_{a e}$ is efficiency of the national average power generation in China, $Q_{h_{c}}=35 \% ; \quad \eta_{g e}$ is efficiency of the grid transmission [10], $\eta_{g e}=92 \% ; \quad \eta_{e e}$ is efficiency of the electric water heater heating, $\eta_{e e}=95 \% ; C O P_{a p}$ is heating coefficient of performance of air heat pump, $C O P_{a p}=360 \%[11]$.

Table 1 shows the energy efficiency and environmental benefits of traditional electric heating dishwashers and multifunctional heat pump dishwasher respectively. As we can seen from table 1, the energy consumption of primary energy for electric heating dishwasher is $4.71 * 10^{5} \mathrm{~kJ}$ and that of multifunctional heat pump dishwashers is $1.24 * 10^{5} \mathrm{~kJ}$. The primary energy consumption of multifunctional heat pump dishwasher only accounts for the energy consumption of traditional electric heating $26.32 \%$. Comparing carbon dioxide emissions between traditional electric heating dishwasher and multifunctional heat pump dishwasher, traditional electric heating dishwasher is $40.07 \mathrm{~kg}$, and multifunctional heat pump dishwasher is $10.55 \mathrm{~kg}$, multifunctional heat pump dishwasher only accounts for $26.33 \%$ of the energy consumption of traditional electric heating.

Table 1 Comparison of energy efficiency and environmental benefits between traditional electric heating and multifunctional heat pump dishwasher

\begin{tabular}{ccc}
\hline Project & $\begin{array}{c}\text { Traditional electric heated } \\
\text { dishwasher }\end{array}$ & $\begin{array}{c}\text { Multifunctional heat pump } \\
\text { dishwasher }\end{array}$ \\
\hline Energy type & Electricity & Electric and air source energy \\
Energy of per calorific value & 3600 & 3600 \\
& $\mathrm{KJ} /(\mathrm{kW} . \mathrm{h})$ & $\mathrm{KJ} /(\mathrm{kW} . \mathrm{h})$ \\
Primary energy consumption / kJ & $4.71 * 10^{5}$ & $1.24^{*} 10^{5}$ \\
Energy Consumption / $\mathrm{kWh}$ & 130.83 & 34.44 \\
Price / Yuan / degree & 0.63 & 0.63 \\
Operating cost & 82.43 & 21.70 \\
\hline
\end{tabular}


Table 2 Comparison of operating costs between traditional electric heating and multifunctional heat pump dishwasher

\begin{tabular}{|c|c|c|c|}
\hline & Project & $\begin{array}{c}\text { Traditional electric heating } \\
\text { dishwasher }\end{array}$ & $\begin{array}{l}\text { Multifunctional heat pump } \\
\text { dishwasher }\end{array}$ \\
\hline & nergy type & Electricity & Electric and air source energy \\
\hline Th & al efficiency $/ \%$ & 95 & 360 \\
\hline Primary & gy consumption / kJ & $4.71 * 10^{5}$ & $1.24 * 10^{5}$ \\
\hline Equival & o standard coal / kg & 16.07 & 4.23 \\
\hline \multirow{3}{*}{$\begin{array}{l}\text { Pollution } \\
\text { situation }\end{array}$} & Carbon dioxide / kg & 40.07 & 10.55 \\
\hline & Sulfur dioxide / kg & 1.21 & 0.32 \\
\hline & Nitrogen oxides / kg & 0.60 & 0.16 \\
\hline
\end{tabular}

According to the national standard of household electricity price in China, the price of electricity is 0.63 Yuan $/ \mathrm{kWh}$. Table 2 shows the comparison of operating costs between traditional electric heating dishwasher and multifunctional heat pump dishwasher. The running cost of conventional electric heating dishwasher is 82.43 Yuan per times and that of multifunctional heat pump dishwasher is 21.70 Yuan. The primary energy consumption of multifunctional heat pump dishwasher is reduced by $73.67 \%$ compared with that of the traditional electric heating.

\section{Conclusion}

According to analyses on performance of the system under four different working conditions as hot water, hot air, cold air and high temperature water for the multifunctional heat pump system used for dishwasher, the following conclusions are drawn:

(1)The COP of the hot air system, hot water system and high temperature water system will increase as the ambient temperature increases, and its power consumption of compressor will reduce.

(2) COP of the novel multifunctional heat pump system for dishwashers is higher than 3.2, which meets the energy-saving requirements.

(3)According to the comparison on energy efficiency, environmental benefit and operating cost between the traditional electric heating dishwasher and the novel multifunctional heat pump dishwashers, it is concluded that the primary energy consumption, the primary carbon dioxide emissions and running cost of the novel multifunctional heat pump dishwasher are $1.24 * 10^{5} \mathrm{~kJ}, 10.55 \mathrm{~kg}$ and 21.70 Yuan respectively, which are lower than the traditional electric heating dishwasher as $73.67 \%, 73.67 \%$ and $73.67 \%$.

\section{Acknowledgment}

This project was financially supported by the State Key Program of National nature Science of China (Grant no.51134005); and the National Natural Science Foundation of China (Grant no.51274098); and Hunan Provincial Natural Science Foundation of China (13JJ6057); Jiangxi Provincial Education Science Research Project of China(GJJ181024).

\section{References}

[1] S.J. Rui, H. Zhang, Y.Q. Wu, Experimental research of single-stage compression reheating cycle of non-azeotropic mixture, Journal of Refrigeration, 33, 6 (2012): 63-67.

[2] J.B Chen, J.S. Yao, Y.1. Kang, X. Han, H. Li, Y. Wang, Study on control stability of cascade air source heat pump system, Journal of Refrigeration, 35, 1 (2014): 38-45.

[3] Y.S. Yu, X.Q. He, H.M. Jiang, P.H. Qian, Experimental Study on the Heating Performance of Single-stage and Dual-stage Air-source Heat Pumps, Journal of Nanjing University of Science and Technology, 36, 6 (2012): 1036-1041.

[4] Z. X. Zhang, R. Cheng, Y. P. Zheng, Experimental study on the high temperature section of cascade heat pump, Journal of Chemical Industry and Engineering, 28, 1 (2014): 4-6.

[5] B. Shen, J. New, V. Baxter, Air source integrated heat pump simulation model for EnergyPlus, Energ Buildings, 156(2017): 197-206.

[6] M. Almahdi, I. Dincer, M.A. Rosen, A new integrated heat pump option for heat upgrading in $\mathrm{Cu}-\mathrm{Cl}$ cyclefor hydrogen production, Comput Chem Eng; 106(2017): 122-132.

[7] X.D. Wang, C.Y. Zhang, Z. Zhang, B.B Sun, Experimental research on the performance of air source heat pump, HUVT; 44, 5 (2014): 119-123.

[8] C.Y. Cho, J.M. Choi, Experimental investigation of a multi-function heat pump under various operating modes, Renew Energ; 54(2013): 253258.

[9] B. FU, L. Liu, Energy-saving analysis of airsource heat pump hot water unit, Public Engineering Design, 07 (2008): 80-82.

[10]Q.1. Zhang, Y.L. Li, B.S. Liu, H.F. Di, The adaptability of low temperature air source heat pump heating mode in northern heating area. Building Science, 3, 02 (2015):140-145.

[11] Standardization Regulatory Committee of China. Energy efficiency rating and energy efficiency rating of heat pump water heater (GB295412013); (2013) 